\title{
EFFECT OF ONE VERSUS TWO IMPLANT RETAINED OVERDENTURES ON BITING FORCE, MASTICATORY EFFICIENCY AND PATIENT SATISFACTION
}

\author{
Mohamed H. S. Abdelnabi*
}

\begin{abstract}
Background: Single symphyseal implant-retained overdentures have been suggested as an alternative to the standard two implant treatment. There is, however, a need for more studies to compare the functional and patient outcome aspects of both treatment modalities.
\end{abstract}

Objective: The aim of this prospective study is to compare the effect of single symphyseal versus two implant mandibular overdentures on the objective variables: maximum bite force (MBF) and masticatory efficiency (ME), in addition to patient satisfaction (PS) as a patient based outcome.

Materials and methods: A total of 60 completely edentulous male patients were initially included in this investigation: 50 from three previously published studies and simultaneously participating in this study in addition to 10 new subjects. 53 participants concluded the study. All subjects received new conventional complete dentures. After 2 months adaptation period, patients allocation was carried out into 3 groups based on the type of implant retained mandibular overdenture that will be constructed: Group (1) single symphyseal implants with locator attachments; Group (2) two interforaminal freestanding implants with locator attachments; Group (3) two splinted interforaminal implants with bar-clip attachments. A capacitive sensor was used to evaluate unilateral MBF. Sieve method was implemented for ME assessment. PS was evaluated in 7 functions using visual analogue scale. MBF and ME were assessed 2 months after conventional complete dentures insertion (baseline); and then at 6months, 1year and 2 years after implant functional loading. PS was monitored at baseline and 24 months after implant loading. Level of statistical significance was set at $\mathrm{p}<0.05$.

Results: All subjects reported a significant improvement in MBF, ME and most of PS variables when implants were used in comparison to the baseline status with conventional dentures. No significant differences were observed between MBF and ME findings among the three groups after implant placement. PS function of maintaining hygiene showed less favourable outcomes in group 3 .

Conclusions: Mandibular implant retained overdentures in contrast to complete dentures improved maximum bite force, masticatory efficiency and patient satisfaction. Outcomes with one and two splinted and unsplinted implants were comparable. Bars, however, complicated hygiene.

* Associate Professor, Oral and Maxillofacial Prosthodontics Dept., Faculty of Dentistry, King Abdulaziz University, Jeddah, Saudi Arabia; Department of Removable Prosthodontics, Faculty of Dentistry, Minia University. 


\section{INTRODUCTION}

Management of complete edentulism is one of the challenges in dentistry. Higher life expectancy has resulted in an increase in the overall number of completely edentulous patients despite improved methods of of caries control and tooth preservation. Tooth loss is even more among individuals with low income ${ }^{1}$. Edentulism affects oral and general health, has a negative impact on the overall quality of life, and can thus be regarded as a handicap ${ }^{2}$. Conventional complete dentures have limitations, especially in the mandible. Limited retention and stability, in addition to sensitivity or pain of the mucoperiosteum covering the residual ridges, compromised bite force and consequently masticatory efficiency are among the commonly reported shortcomings ${ }^{3-5}$.

Introduction of dental implants has greatly improved treatment outcomes of complete edentulism. There is an emerging consensus, based on biological success and psychosocial satisfaction, that two implants retained mandibular overdentures opposed by maxillary complete dentures should be the standard of care for completetly edentulous patients ${ }^{6}$. Enhanced denture stability, masticatory function, patient satisfaction and quality of life are among the advantages ${ }^{2,7,8}$. A number of studies ${ }^{7,9}$ have shown that patient satisfaction is equally high with fixed or removable implant prosthesis. Higher degree of prosthesis stability resulted in an enhancement in neuromuscular response $\mathrm{e}^{10}$.

Recently, there is growing evidence that single symphyseal implants can efficiently retain mandibular dentures. This approach decreases cost obstacles and has additional potential surgical advantages over the standard two implant alternative. Cost is one of the major concerns in implant treatment. It has been estimated that only one in one thousand partially or completely edentulous individuals worldwide can afford to benefit from this treatment. Midline implant placement simplifies imaging, flap design, avoids the mental foramen, the inferior alveolar nerve and its branches ${ }^{11-14}$.

Reviewing the dental literature revealed the limited number of published research that objectively and subjectively compared between one and two implant retained mandibular overdentures ${ }^{14,15}$. The aim of this study was thus to evaluate the effect of one versus two implants retained mandibular overdentures on maximum bite force, masticatory efficiency and patient satisfaction in completely edentulous patients.

\section{MATERIALS AND METHODS}

A total of 60 completely edentulous male patients were initially included in this investigation: 50 from three previously published studies ${ }^{16-18}$ and were simultaneously participating in this study in addition to 10 new subjects. The additional cases were enrolled to have near equal group sizes for meaningful statistical analyses. The age ranged from 49-64 with a mean age of 56. Patients were selected from the outpatient's clinic of Minia University and from the author's private clinic. The study protocol and procedures were in accordance with the ethical guidelines of the university. The study took place in the extended period from 2010-2015.

The procedures followed for case screening, recruitment and prostheses construction, have been described in previous articles ${ }^{16-18}$. All subjects were completely edentulous for a minimum of 2 years and with conventional complete denture experience of at least 1 year. Possible alternative treatments were explicitly explained to all participants. Verbal and written material explaining the different phases of the study were submitted. Written approval consents were signed as a pre-requisite for enrollment.

Patients were asked to respond to both a written and verbal questionnaire covering their medical history to rule out any systemic conditions that can affect the outcome of implant treatment. Participants were screened to exclude diabetes 
mellitus by examining post-prandial blood glucose. None of the enrolled subjects received radiotherapy in the head and neck region. Receiving bisphonates for osteoporosis was an exclusion criterion. 49 of the selected subjects were non-smokers and 11 smoked less than 10 cigarettes a day. Radiographic panaromic screening assessment was carried out to insure that there is enough inter-foraminal bone height to accommodate $13 \mathrm{~mm}$ implants. Level of residual ridge resorption (RRR) in the posterior section of the denture bearing area was assessed by comparing bone height with the level of the mental foraminae ${ }^{14}$. Cases with more than moderate RRR were excluded.

Residual ridges showed no excessive undercuts and had no redundant mucoperiosteum. All included subjects did not suffer from xerostomia. Their medical history was checked to ensure that participants did not receive medications that compromise salivary flow. The mechanically stimulated salivary flow was determined by a standardized method by instructing the patient to chew on a piece of tasteless parafilm ${ }^{19}$. Patients were requested to expectorate in a pre-weighted container at 30 seconds intervals over a period of 5 minutes. Salivary flow was calculated in terms of $\mathrm{ml} \cdot \mathrm{min}^{-1}$. All subjects were non-bruxers, had no temporomandibular problems, had Angle class I jaw relationship and adequate inter-arch space to accommodate the attachments for the mandibular implant-retained overdentures.

New maxillary and mandibular complete dentures were constructed for all patients. The technique of new conventional complete denture construction was described in previously published $\operatorname{articles}^{16-18}$. Patients were instructed to return for periodic recalls after denture delivery to eliminate any post-insertion problems. Clinical remounts were carried out at these check-up appointments.

After two months of regular conventional complete denture use, patients were recalled for implant placement. Participants were allocated using computer based randomization into 3 groups based on the type of implant retained mandibular overdenture that will be constructed: Group (1) single symphyseal implants with locator attachments (24 participants); Group (2) 2 interforaminal freestanding implants with locator attachments (16 participants); Group (3) 2 splinted interforaminal implants with bar-clip attachments (20 participants) (Fig.1). Baseline statistical analyses of potential confounding variables including bone height as revealed in radiographic assessment, age and quality of previous denture experience were carried out with no statistical differences between the three groups.

The mandibular denture was then duplicated in clear acrylic resin mixed with barium sulphate radio-opaque material. The duplicate served as a radiographic template. Cone beam was used to assess in $3 \mathrm{D}$ bone availability at the suggested implant sites both quantitatively and qualitatively. Exact implant osteotomy sites were determined and the template was then altered to function as a surgical stent.

Implants with rough surface, dual-acid etched using hydrochloric and sulfuric acids, were used in this study (Osseotite XP Certain, Biomet 3i, Palm Beach Gardens, FL, USA). A standardized surgical procedure was implemented for all investigated groups. Details of the surgical technique were mentioned in previous articles ${ }^{16-18}$. It is worth mentioning that the selection of the final drill size was based on bone quality. In type 1 bone, the final drill size was $3.25 \mathrm{~mm}$, in type 2 bone 3.0 $\mathrm{mm}$, and in type 3 bone a $2.75-\mathrm{mm}$ final drill was used $^{20}$. None of the included subjects were type 4 . Implant surgery drill sequence was followed with extreme care to avoid penetration of the lingual or inferior cortex ${ }^{13}$. A countersinking technique was utilized in order for the implant to engage as much cortical crestal bone as possible ${ }^{20}$. Primary implant 
stability was controlled by quantifying implant insertion torque. Insertion torque was measured with a drill unit (Osseocare ${ }^{\mathrm{TM}}$ Nobel Biocare $\mathrm{AB}$, Göteborg, Sweden). A minimum insertion torque of $45 \mathrm{Ncm}$ before the final seating of the implant was an inclusion pre-requisite for cases that will receive single symphyseal implants and $35 \mathrm{Ncm}$ for cases that will receive 2 implants.

\section{Prosthetic phase}

Most of implants were immediately loaded within 48 hours from implant placement. A group of single symphyseal implants were loaded according to a conventional protocol after 4 months of implant placement because these subjects were simultaneously participating in a study comparing different loading regimens ${ }^{18}$. To avoid any possible consequences of the differences in loading protocols on the outcome of the study at hand, post implant placement objective assessement of MBF and ME was first carried out after 6 months after full functional loading of successfully osseointregrated implants. PS as a patient based outcome was even assessed 24 months after full functional loading.

Details of the prosthetic technique for both locators and bars were discussed in previous $\operatorname{articles}^{16-18}$. For groups 1 and 2, proper locator abutment collar height (Zest Anchors LLC, Escondido, CA, USA) was selected for each implant after measuring the soft tissue thickness. To avoid soft tissue complications, a collar height of at least $2 \mathrm{~mm}$ above the mucosa was used ${ }^{21,22}$ (Fig. 1). Locator abutments were torqued into the implants at $20 \mathrm{Ncm}$, using a torque device. The interfaces were radiographed to verify complete seating of the abutments on the implants. A direct chair side pick up technique was implemented. Any necessary occlusal or tissue adjustments were made.

The prosthetic protocol for the freestanding implants using locator attachments of group II was similar to that of single implants with locator attachments of group I. Parallelism of implants was found to be acceptable and thus regular locator matrices were used.

Implants with locator attachments of the conventionally loaded group were protected with cover screws, flap sutured and left for uninterrupted healing and osseointegration for 4 months. The intaglio surface of the mandibular denture was generously relieved, and tissue conditioner (Viscogel, DeTrey, Konstanz, Germany) applied. Instructions similar to those given in the immediately loaded group were given to the patients. At the time of second surgery, the implant was exposed using tissue punch. Prosthetic procedure was then carried out similar to that of the first group.

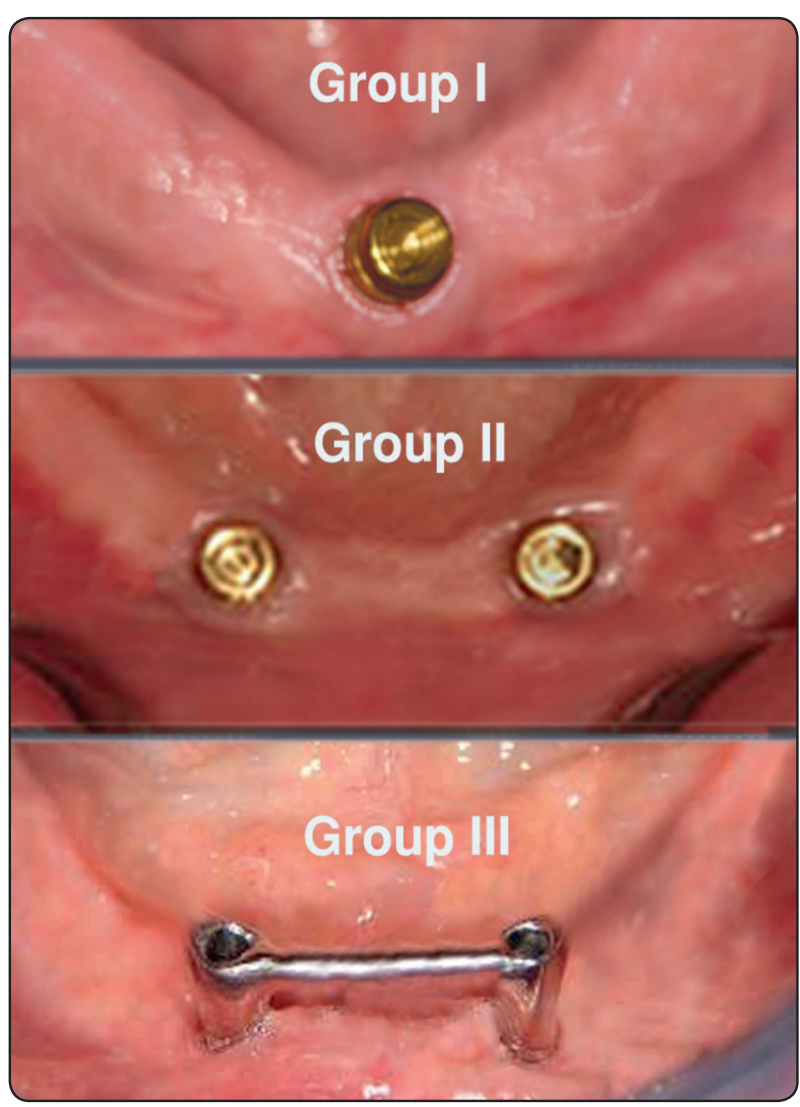

Fig. (1) 6 months after full functional implant loading. Group I: Single symphyseal implant with locator attachment; Group II: Two interforaminal freestanding implants with locator attachments; Group III: Two interforaminal splinted implants with bar-clip attachments. 
For group 3, proper standard abutment collar height for each implant of the bar group was selected and threaded into place. Abutment implant interface were radiographed to verify complete seating. Standard abutment screws were torqued into the implants at $20 \mathrm{Ncm}$. At this stage the flap was repositioned and sutured. Sterile standard abutment pick-up impression copings were placed onto the abutments. Impression copings were then splinted. Custom impression trays were used for the pick-up impression technique. Round Ackerman bar (Artiglio, Parma, Italy) was then fabricated and configured parallel to the terminal hinge axis (Fig 1). Passive seating of bar on abutments was verified. If a fit discrepancy was found, the bar was cut and indexed intraorally for soldering. Adequate clearance between the bar and the residual ridge was checked to allow hygiene aids to access that area efficiently. The bar clip was picked up with self curing acrylic resin as recommended by the manufacturer.

Patients were instructed never to sleep with the prosthesis. They were supplied with oral hygiene aids. The importance of plaque control was emphasized. Participants were informed, both verbally and in written consent forms, that negligence in maintaining oral hygiene or adhering to the follow up will result in exclusion from the study. Regular use of the removable prosthesis in all phases of the study was a prerequisite for the participant to continue in this investigation.

A regular clinical examination was carried out on monthly basis for implant retained prosthetic rehabilitations. Patients who had further complaints were instructed to schedule an appointment whenever needed. Prosthesis tissue adaptation, occlusion and the condition of the retentive mechanisms were monitored. At each session, patients were asked to bite maximally and any areas of pain or discomfort were corrected. The fitting surfaces of the maxillary and mandibular dentures were checked with pressure indicating paste. Relining was carried out whenever needed. Occlusion was corrected using articulating paper for minor corrections. Clinical remounts were conducted when more reliable assessments and corrections were needed. Abutment screws were tightened to the torques recommended by the manufacturer. Retention mechanisms of implant retained overdentures were checked to examine its efficiency and any patient complaint in this respect was addressed.

\section{MBF, ME and PS assessment}

Capacitive sensor was used to assess unilateral MBF. Sieve method was implemented for ME. PS was evaluated in 7 functions using visual analogue scale (VAS). The objective variables (MBF and ME) were assessed with the conventional complete dentures at baseline directly before implant placement surgery; and then at 6months, 12 and 24 months after implant full functional loading. PS was monitored at baseline and 24 months after implant loading.

The iLoad Mini miniature load cell kit (Loadstar Sensors, Fremont, CA, USA.) was used to measure the maximum bite force. The kit included a load cell with a rounded dome on top and with a flat bottom adapter, a DQ1000U frequency to USB interface that converts the frequency output from mini load cell into USB output and LV100 loadVUE load cell display software which displays, logs and plots the data on a PC in real time. The assembly is fully calibrated in compression mode. This type of load cells has the advantages of using capacitive sensing techniques. It offers high sensitivity in small sized rugged tough packages that can withstand much higher loads than a similar electric resistor sensor, that implements resistance strain gauge technology. The noise levels are reduced. The improved signal to noise ratio results in a signal of better quality. This reduction allows to pack more features into the sensors - in the form of built in digital communication modules with USB/WiFi/XBee 
Wireless/Serial protocols, algorithms to convert raw signals into readily usable calibrated data and easy to use ASCII command set to access the finished data $^{23}$.

Vertical MBF was measured between the first molars on each side. The bite force transducer was covered with a layer of polyvinyl siloxane dental impression material (Exafast, GC, IL, USA). The PVS layer fitted the profile of each subject's teeth and guaranteed a reproducible position of the load cell at the different measurement sessions. A cube shaped PVS block with imprints of teeth of the other side was placed during MBF measurements to achieve occlusal stability. As recommended by the manufacturer, the load cell was allowed to warm by connecting it to the power supply for at least 30 minutes before the measurement procedure. The sensor was then connected to PC through USB cable. The patient was seated in an upright position. Each measurement was repeated 3 times. The highest values for each side were recorded. The average for the right and left sides for each patient were calculated. A relaxation period of 10 minutes was given to obtain reliable MBF values ${ }^{24,25}$.

ME was evaluated using filtered food remnant weight sieving method ${ }^{26,27}$. Dried peanuts were weighted and packed in sealed plastic bags $2.0 \mathrm{~g}$ each. Participants were directed to chew the prepacked $2.0 \mathrm{~g}$ of peanuts in $30 \mathrm{~s}$ and then to expectorate the bolus in a dry container. The collected material was sieved through a filter with $2.4 \mathrm{~mm}$ diameter holes. The remnants of the peanuts, that did not pass through the sieve, were dried in a desiccator set at $60^{\circ} \mathrm{C}$ for $6 \mathrm{~h}$ and then weighed. The formula used to determine the masticatory efficiency in terms of a percentage was as follows: Masticatory efficiency $=[($ Total weight - Remnant weight $) /$ Total weight $] \mathrm{x}$ $100 \%$. This procedure was repeated 3 times for each test condition and the average was used to represent the masticatory efficiency.

Enrolled participants were requested to assess their conventional complete dentures 2 months after denture insertion. A second patient satisfaction assessment was carried out 24 months after implant loading of the implant retained overdentures. A $100 \mathrm{~mm}$ Visual Analogue Scale (VAS) was used to rate the prostheses. Descriptors were anchored at each end of VAS, zero corresponds to "completely dissatisfied", and the $100 \mathrm{~mm}$ opposite end represents "completely satisfied". Patients were instructed to rate the following variables: comfort, esthetics, ability to speak, stability, ease of chewing, hygiene maintenance and overall satisfaction.

All subjects were instructed to complete a sociodemographic questionnaire including: age, gender, marital status, educational level and occupation. Statistical analyses were carried out to ensure that these potential confounding variables did not affect participants' PS scores.

\section{Statistical analyses}

Statistical analyses for the obtained results were conducted with SPSS (Statistical Package for Social Sciences) (Version 15.0 for Windows, SPSS). Relevance of data to normal distribution was analyzed using Kolmogorov - Simrnov test. Data were displayed as means and standard deviations. ANOVA inferential statistical test followed by post hoc Duncan multiple range test was implemented for the normally distributed MBF and ME results. Non-parametric Kruskal Wallis succeeded by Dunn post hoc test were carried out for patient satisfaction VAS scores as their distribution did not conform to a normal distribution. The relationship between MBF and ME was assessed by Spearman rho correlation. Significance level for statistical analyses was set at $\mathrm{p}<0.05$.

\section{RESULTS}

53 of the initially 60 enrolled participants concluded the study. 21 from the 24 participants of group I participated in the full duration of the 
study. One case did not show up, and another was excluded because of poor hygiene maintenance and consequent implant failure. A case did not achieve the needed $45 \mathrm{Ncm}$ insertion torque, and was shifted to another treatment modality. All 16 subjects of group II concluded the study. In group III, 16 out of the 20 subjects were available for the 24 months period of the study. Contact was lost with one participant, another case showed poor adherence to oral hygiene regulations and was thus excluded. 2 other cases did not achieve the needed $35 \mathrm{Ncm}$ insertion torque pre-requisite and were managed by a different approach.

MBF results showed a significant increase after implant loading as values were nearly doubled in comparison to readings obtained with conventional complete dentures. The differences between MBF after 6, 12 and 24 months of implant loading were insignificant. Comparisons between different implant groups were also insignificant (Table 1, Fig. 2).

TABLE (1) Maximum bite force in Newtons before and after implant placement.

\begin{tabular}{|c|c|c|c|c|}
\hline \multirow{3}{*}{ Group } & \multicolumn{4}{|c|}{ Maximum Bite Force in Newton (Mean \pm SD) } \\
\hline & \multirow{2}{*}{$\begin{array}{c}\text { Before } \\
\text { implant } \\
\text { placement }\end{array}$} & \multicolumn{3}{|c|}{ After implant placement } \\
\hline & & $6 \mathrm{~m}$ & $12 \mathrm{~m}$ & $24 \mathrm{~m}$ \\
\hline $\mathrm{I}(\mathrm{n}=21)$ & $72 \pm 29^{a}$ & $138 \pm 51^{b}$ & $141 \pm 49^{b}$ & $140 \pm 38^{b}$ \\
\hline $\mathrm{II}(\mathrm{n}=16)$ & $79 \pm 32^{a}$ & $130 \pm 44^{b}$ & $145 \pm 54^{b}$ & $136 \pm 29^{b}$ \\
\hline $\operatorname{III}(n=16)$ & $68 \pm 21^{a}$ & $142 \pm 59^{b}$ & $139 \pm 61^{b}$ & $144 \pm 40^{\mathrm{b}}$ \\
\hline
\end{tabular}

$m=$ month; $n=$ sample size; Values with dissimilar letters in rows (within groups) show significant statistical differences. Differences in columns (between groups) were statistically insignificant. $(p<0.05)$.

ME was expressed as percentage of comminuted food particles that passed through the sieve holes. Significant improvement was observed with implant

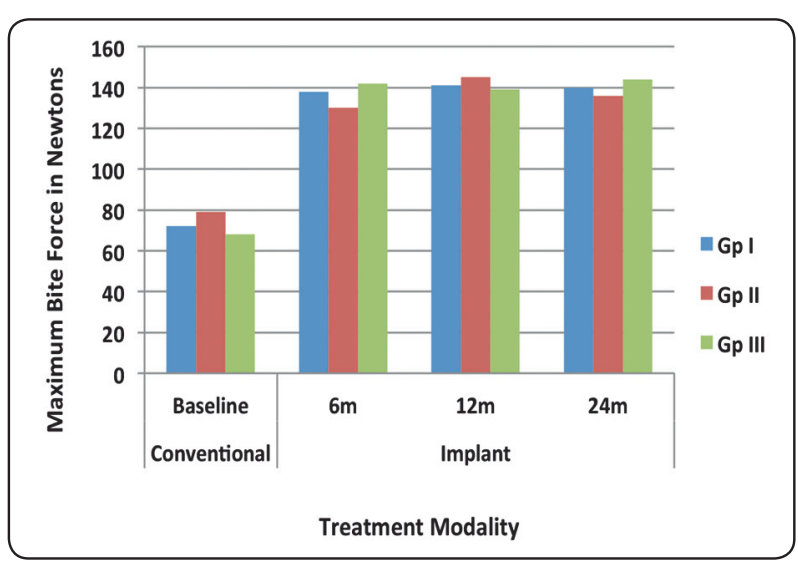

Fig. (2) Maximum bite force in Newtons before and after implant placement. ( $m=$ month; gp=group).

retained overdentures in contrast to conventional complete dentures. The achieved improvement was stable after implant loading with no significant differences between values recorded after 6, 12, 24 months thereafter. Differences between implant groups were insignificant. The data dispersion as expressed in terms of standard deviation was around quarter to third of the mean (Table 2, Fig. 3).

Table (2) Masticatory efficiency before and after implant placement.

\begin{tabular}{|c|c|c|c|c|}
\hline \multirow{3}{*}{ Group } & \multicolumn{4}{|c|}{ Masticatory efficiency $\%($ Mean \pm SD) } \\
\hline & & \multicolumn{3}{|c|}{ After implant placement } \\
\hline & Baseline & $6 \mathrm{~m}$ & $12 \mathrm{~m}$ & $24 \mathrm{~m}$ \\
\hline $\mathrm{I}(\mathrm{n}=21)$ & $47 \pm 12^{\mathrm{a}}$ & $67 \pm 17^{b}$ & $66 \pm 15^{b}$ & $67 \pm 15^{b}$ \\
\hline $\mathrm{II}(\mathrm{n}=16)$ & $42 \pm 16^{\mathrm{a}}$ & $64 \pm 12^{b}$ & $67 \pm 19^{b}$ & $66 \pm 17$ \\
\hline $\operatorname{III}(n=16)$ & $45 \pm 14^{\mathrm{a}}$ & $68 \pm 18^{b}$ & $65 \pm 14^{b}$ & $69 \pm 18$ \\
\hline
\end{tabular}

$m=$ month; $n=$ sample size; Values with dissimilar letters in rows (within groups) show significant statistical differences. Differences in columns (between groups) were statistically insignificant. $(p<0.05)$ 


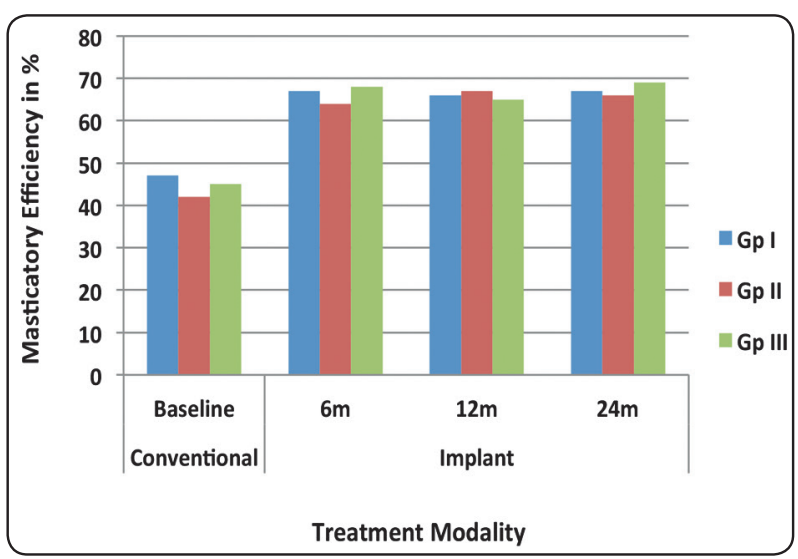

Fig. (3) Masticatory efficiency before and after implant placement. ( $\mathrm{m}=$ month; gp=group).

Differences in salivary flow between the three groups were statistically insignificant. Salivary flow was expressed in terms of $\mathrm{mL} \cdot \mathrm{min}^{-1}$ (Group $\mathrm{I}=2.95$ \pm 0.84 ; Group II = $3.19 \pm 0.98$; Group III $=2.79$ \pm 0.59 ). Salivary flow plays an important role in ME. This factor was thus excluded as a potential confounding variable as there were no significant differences between the three groups.

Analysis of the relationship between MBF and ME implementing Spearman coefficient revealed a significant correlation $(\mathrm{p}<0.05)$.
Patient satisfaction VAS scores improved in 4 of the 7 assessed variables when comparing the conventional complete denture with the implant retained overdentures. A highly significant improvement $\quad(\mathrm{p}<0.001)$ was observed in stability, ease of chewing and overall satisfaction. Enhancement in comfort was significant $(\mathrm{p}<0.05)$. Changes in ability to speak and in esthetics were insignificant. In the implant groups with the exception of group III with the bars, changes in hygiene maintenance were insignificant. Some patients in the bar group reported difficulties in maintaining hygiene underneath the attachment and were thus less satisfied. Most of the VAS scores in the three implant groups, when compared against each other, were statistically insignificant. An exception is hygiene maintenance variable in group III that was less satisfactory in comparison to the other configurations (Table 3). Potential confounding variables including: age, marital status, educational level and occupation were statistical insignificant between the three study groups. The reported results of this study could thus be contributed to the prosthetic variables.

TABLE (3) Patient satisfaction VAS scores before and after implant placement.

\begin{tabular}{|c|c|c|c|c|c|c|}
\hline \multirow{3}{*}{ Variable } & \multicolumn{6}{|c|}{ Patient satisfaction VAS scores (Mean $\pm \mathrm{SD}$ ) } \\
\hline & \multicolumn{3}{|c|}{ Conventional Complete Dentures (Baseline) } & \multicolumn{3}{|c|}{24 months after implant placement } \\
\hline & Group I & Group II & Group III & Group I & Group II & Group III \\
\hline Comfort & $64 \pm 15$ & $61 \pm 12$ & $59 \pm 12$ & $82 \pm 26 *$ & $88 \pm 24 *$ & $85 \pm 29 *$ \\
\hline Esthetics & $88 \pm 20$ & $84 \pm 22$ & $89 \pm 24$ & $90 \pm 31$ & $94 \pm 29$ & $82 \pm 22$ \\
\hline Ability to speak & $85 \pm 19$ & $81 \pm 20$ & $88 \pm 21$ & $89 \pm 27$ & $92 \pm 32$ & $91 \pm 29$ \\
\hline Stability & $61 \pm 14$ & $65 \pm 16$ & $64 \pm 16$ & $88 \pm 21 * *$ & $90 \pm 28 * *$ & $92 \pm 34 * *$ \\
\hline Ease of chewing & $64 \pm 16$ & $62 \pm 19$ & $59 \pm 18$ & $84 \pm 25 * *$ & $88 \pm 29 * *$ & $91 \pm 31 * *$ \\
\hline Hygiene maintenance & $88 \pm 24$ & $92 \pm 28$ & $90 \pm 27$ & $86 \pm 28$ & $89 \pm 31$ & $81 \pm 20 *$ \\
\hline Overall satisfaction & $61 \pm 11$ & $64 \pm 15$ & $60 \pm 14$ & $88 \pm 26 * *$ & $91 \pm 34 * *$ & $92 \pm 32 * *$ \\
\hline
\end{tabular}

VAS= Visual Analogue Scale; $*$ = statistically significant differences between values in the same row at p<0.05; **= high statistically significant differences between values in the same row at $p<0.001$. 


\section{DISCUSSION}

In this study, MBF and ME were used to objectively assess the functional state of the masticatory system. Fontijn-Tekamp et al. ${ }^{3}$ and Hatch et al. ${ }^{28}$ have reported the large influence of bite force on masticatory performance in subjects with conventional complete dentures, overdentures as well as natural dentition. It was concluded that bite force explains over $60 \%$ of variance in masticatory performance. In the study at hand a significant correlation was found between MBF and ME.

Reviewing the dental literature revealed that a number of variables were reported to affect MBF including: occlusal factors ${ }^{29}$, factors related to dental prostheses ${ }^{30}$, implant treatment ${ }^{31}$, temporomandibular disorders (TMDs) $)^{32}$ and neuromuscular disease ${ }^{33}$. All subjects included in this study were free of TMDs and neuromuscular disease to exclude the adverse effects of such factors on the study outcomes.

When comparing and contrasting studies assessing MBF it is important to critically analyze the methodology of the recording technique ${ }^{29}$. Important factors include location of MBF measurement within the dental arch (incisors, premolars or molars) ${ }^{34-36}$, number of teeth included ${ }^{36}$, dimensions of the bite force transducer (thin pressure-sensitive sheet versus bite transducer) ${ }^{37,38}$. In the study at hand the same calibrated transducer was used throughout the study. A customized layer of impression on surfaces of the transducer contacting the occlusal surfaces of teeth was used to ensure that the transducer was positioned in the same location for each patient at the different experimental conditions. This technique has been implemented by van Kampen et al. ${ }^{31}$ and van der Bilt et al. ${ }^{39}$. Another significant variable is whether the measurement was conducted unilaterally or bilaterally ${ }^{40}$. Bilaterally measured MBF was reported to be $30 \%-40 \%$ larger than the unilaterally measurements ${ }^{41}$. The values of unilateral MBL in the study at hand are comparable to those reported by other studies measuring MBL unilaterally ${ }^{24,25}$ and nearly $30-40 \%$ less than studies measuring MBF bilaterally ${ }^{31,39}$.

A number of studies have also outlined the effect of gender on MBF with males showing significantly higher values $35,36,38,40$. In this study, all participants were males, so gender as a confounding variable was excluded.

In our study with the relatively limited sample size, effect of age on the assessed parameters was insignificant. Similar results were reported by Bilhan et al. ${ }^{42}$ and Geckili et al. ${ }^{24,25}$. A number of studies reported a decrease of MBF with age $28,34,38,41,43$. The correlation coefficient was small but still significant. It was thus reported that age can explain less than $10 \%$ of the variance of bite force. A study ${ }^{28}$ considered that age has an indirect effect on bite force which was caused by decrease in the occlusal units. In the study at hand, the number of occluding units was constant, thus this might have minimized the effect of age.

Inadequate retention and stability of conventional complete dentures result in reduced bite forces, which consequently compromise chewing performance ${ }^{39}$. In the study at hand, MBF with complete dentures wee nearly half that of patients with implant retained overdentures irrespective of the number of implants. Reviewing the dental literature revealed that unilateral MBF in complete denture wearers ranged from 77 to $135 \mathrm{~N}$. The reduced $\mathrm{MBF}$ in complete denture wearers may be even less than that needed to penetrate some varieties of natural foods as boiled meat $(80 \mathrm{~N})$, raw carrots $(118 \mathrm{~N})$ and rye bread $(167 \mathrm{~N})^{44}$. Values reported for dentate individuals ranged from 306 to $847^{3,34,44}$. Patient with mandibular implant retained overdentures had a MBF 60 - $200 \%$ higher than their counterparts with conventional complete dentures ${ }^{24,25,31,35,42,45}$. Similar finding is reported in the study at hand. Bakke et al. ${ }^{45}$ followed up a group of patients for 5 years and reported an average increase of MBF 
from $116 \mathrm{~N}$ with conventional complete dentures to $200 \mathrm{~N}$ just 3 months after implementing implants to retain the mandibular overdentures and the MBF was still high to reach 193 after 5 years. Comparable findings were reported by by van der Bilt et al. ${ }^{46}$, who reported an unaltered significant increase in MBF for 10 years after implant placement. It could thus be concluded that implant treatment resulted in an improvement in biting force and consequently masticatory efficiency that lasted for a relatively long time.

In the current study, the number of implants being one or two, and the type of attachment being locator or bar, had an insignificant effect on MBF. The studies that evaluated the influence of implant number and overdenture attachment type on MBF are limited. These support the assumption that implant number and attachment type do not evoke major differences ${ }^{31,35,47,48}$. Fontijn-Tekamp et $\mathrm{al}^{35}$ found no differences in MBF between mainly implant borne trans-mandibular implants and mucosa implant borne overdentures with two IMZ root form implants. Van Kampen et al. ${ }^{31}$ in a cross sectional study reported no significant difference in MBF between two implant retained mandibular overdentures with bar or ball attachments. They found significantly higher values for ball attachments when compared to magnets. The increase, however, was only $36 \mathrm{~N}$, which was considered to be limited. Bilhan et al. ${ }^{42}$ compared MBF in mandibular implant overdentures with the following configurations: two implants with locators, two implants with balls, three implants with balls, three implants with bars and four implants with bars. They reported insignificant differences in MBF between these groups despite the variations in implant numbers and attachments type. Van der Bilt et al ${ }^{46}$ compared MBF values for ball and bar retained two implant retained mandibular overdentures and reported comparable MBF values and was irrespective of attachment system. The latter study extended for a 10 year follow up period. A possible interpretation of the insignificant effect of implant number and attachment type is that the maxillary edentulous ridge was rehabilitated with a conventional complete denture without attachments. The retention and stability of the maxillary prosthesis could thus be considered compromised. When patients clench, dislodging of the maxillary denture and possibly pain may be evoked. It is logical to assume that sensitivity or pain of the mucoperiosteum covering the residual ridges limits the MBF in completely edentulous subjects ${ }^{49}$.

Studies that assessed masticatory function implemented both objective and subjective methodologies. Objective masticatory function also termed masticatory performance has been objectively and quantitatively evaluated by determining an individual's capacity to grind, fragment, pulverize and mix a test food after a fixed number of chewing cycles and time. Subjective assessment is conducted by asking patients questions concerning chewing food $^{40}$.

A diversity of methods has been used to objectively evaluate masticatory performance. In the study at hand, and in the majority of chewing performance studies, the comminuted food was sieved to determine the degree of food breakdown. Patients were instructed to chew pre-weighed fixed amounts of peanuts for 30 seconds. A similar methodology has been implemented by Cheng et al. ${ }^{26,27}$ Other studies used synthetic material to avoid possible variations in consistency due to seasonal and geographical variations ${ }^{3}$. It was however preferred to use a natural product purchased from a single supplier and stored at constant temperature and humidity in closed packages. The advantage was that participants were accustomed with that normally consumed product. It is worth mentioning that among healthy individuals, data dispersion expressed in terms of standard deviation was reported to be relatively high. This finding was attributed to large individual variations ${ }^{28,50}$. Hatch et 
al. ${ }^{28}$ reported the standard deviation to be nearly half the value of the mean in a group of more than 600 dentate subjects after 20 chewing strokes on peanuts. In our study with a relatively homogenous sample, the standard deviation ranged between quarter and third of the mean. Other methods have also been used to evaluate masticatory performance including colour changes in test food usually chewing gum ${ }^{51}$, sugar loss from chewing gum ${ }^{52}$, release of dye when chewing raw carrots using a colorimeteric method ${ }^{53}$, quantification of colour changes by photometric methods ${ }^{54}$, and by optical scanning of chewed particles ${ }^{55}$. Another widely used methodology is the evaluation of the ability to mix and knead a food bolus. Test food commonly used are two coloured chewing gums ${ }^{56}$ and paraffin wax ${ }^{57}$. The degree of colour mixing was quantified by optical methods ${ }^{57}$, by visual inspection ${ }^{58}$ or by both approaches ${ }^{56}$. Speksnijder et al.$^{57}$ reported a highly significant correlation between outcomes of the comminution and the mixing ability tests and recommended the latter test in cases with compromised masticatory performance.

Sufficient salivary flow is crucial for efficient chewing. Studies ${ }^{58,59}$ reported that the number of strokes needed prior to swallowing is inversely proportional to salivary flow. The dryer and tougher the food, the more is the need for incorporating saliva to moisten the food bolus and to create a more coherent mass that could be easily swallowed. In the study at hand the amount of salivary flow was among the inclusion criteria. All included subjects had values of salivary flow comparable to that of healthy subjects ${ }^{19}$.

A number of studies reported that loss of posterior teeth ${ }^{50}$ and wearof inefficientconventional removable prostheses $^{34,40,60}$ results in reduced masticatory performance. On the other hand, implant supported and retained prostheses significantly improved masticatory function in edentulous patients ${ }^{3,31,48,61}$. In the study at hand, masticatory efficiency was higher in implant retained overdentures than in conventional complete dentures. This finding was irrespective of implant number or attachment type. The improved masticatory efficiency reflected in the smaller particle size observed in the implemented sieve method. This finding concurs with a number of other studies ${ }^{45,47,62,63}$. Complete denture wearers especially in cases with compromised retention and stability reported have complaints related to masticatory performance ${ }^{40}$. Studies that compared the number of chewing strokes needed to pulverize food to the same degree as that of dentate subjects reported a number between four times ${ }^{3}$, six times ${ }^{60}$ and even as high as eight times more ${ }^{64}$. Complete denture wearers compensate by chewing longer and swallowing coarser food particles ${ }^{49}$.Implant attachments improve denture stability, reduce pain and enable patients to exert higher biting forces and consequently improve masticatory function ${ }^{48}$. Van Kampen et al. ${ }^{47}$ reported that implant retained overdentures resulted in a decrease in the number of chewing cycles needed to halve the test particle size with $47-25$ cycles. Heckmann et al. ${ }^{39}$ investigated the effect of implant retained overdentures on chewing function using methodologies different than that used in the study at hand, and found that variables including: jaw muscle activity, kinesographic parameters (vertical opening, frontal extension and closing velocity) showed values close to that of dentate subjects.

In the study at hand, both the number of implants being one or two, and type of attachment being locator or bar, had an insignificant effect on ME. A similar trend was reported by Geertman et al.$^{61}$, who found out an insignificant difference in ME between mandibular overdentures retained by two permucosal implants and those with transmandibular implants and quadrilateral cantilevered bars. They suggested that improved retention and stability rather than support might play a crucial role in determining the wearer's ability to comminute food. Similarly Tang et al ${ }^{48}$ found out that the number of implants 
retaining and supporting mandibular overdentures whether two or four implants did not influence ME. Van Kampen et al. ${ }^{47}$ compared conventional complete dentures to two implant mandibular overdentures with balls, bars and magnets. The improvement in ME in edentulous subjects between conventional complete dentures and two implant retained mandibular overdentures with balls, bars and magnets was significant. ME with ball and bar attachments were slightly better than that observed with magnets. In a 10 year follow up study, van der Bilt ${ }^{46}$ followed up a number of patients with two implant retained overdentures with ball and bar attachments. ME was measured by instructing participants to chew on cubes of dental impression. The degree of fragmentation of the chewed material was evaluated by sieving. Furthermore, the number of chewing cycles needed to halve the initial particle size was determined. They reported a significant improvement in ME when comparing conventional complete dentures to implant retained overdentures, but insignificant differences in all parameters between ball and bar retained implant retained overdentures. On the other hand, Elsyad et al. ${ }^{65}$ reported increased $\mathrm{ME}$ of overdentures supported by four implants when compared to two implant designs with either ball or bar attachments. Mixing ability of two coloured chewing gums was their implemented methodology. They attributed the results to the possible eating preference of the patients included in their study using posterior occlusion as an eating habit.

A number of factors were reported in the dental literature as potential confounding variables that might affect patient satisfaction assessments. These factors include: age, gender, marital status, educational level and occupation ${ }^{14}$. These variables were identified in socio-demographic questionnaire that participants were instructed to answer. All included subjects were males. Groups were matched as regards the remaining potential confounding variables. Statistical analyses were carried out to ensure that these variables did not affect participants' scores.

Participants in the study at hand assessed their conventional complete dentures two months after denture insertion. It has been reported that this period is adequate for patients adaptation to give stable responses to patient satisfaction questionnaires ${ }^{9}$. The construct and content validity of the questionnaire implemented in this study has been established in previous studies $^{8,9}$. High test re-test reliability has been reported ${ }^{66}$. Tang et al.$^{67}$ has shown that general satisfaction is sensitive enough to reveal small differences between different prosthetic designs implementing implants. General satisfaction was thus used in this study as the primary outcome assessing patient satisfaction. Awad and Feine ${ }^{66}$ reported that comfort, stability, ease of chewing, ability to speak and esthetics were the variables that explained $89 \%$ of the variation in ratings of general satisfaction. These variables were defined as crucial by edentulous patients and by prosthodontists ${ }^{3,68}$.

Patient satisfaction improved significantly in most of the assessed variables after implant placement in comparison to the baseline evaluation with the conventional complete dentures. Esthetics and ability to speak did not improve significantly with the implant placement. Similar findings have been reported in other studies ${ }^{8,69}$. This finding might be attributed to the fact the conventional dentures had enough retention and stability to provide satisfactory phonetics and esthetics. On the other hand, patients with bar retained implant overdentures reported a negative impact on hygiene maintenance. These findings concur with those reported by Naert et al. ${ }^{70}$. In their study, mucositis and hyperplasia were more often in bar in comparison to magnet and ball groups.

The differences between the implant retained groups were insignificant with the exception of oral hygiene. Patients with bar retained implant overdentures reported less level of satisfaction 
with hygiene maintenance. A number of studies ${ }^{14,15}$ similarly reported high level of satisfaction with both single symphyseal and two interforaminalimplants retaining mandibular overdentures opposed by maxillary complete dentures. Kronstrom et al. ${ }^{15}$ in a randomized study reported comparable patient satisfaction findings with immediately loaded mandibular overdentures retained with single symphyseal or two interforaminal implants. Cases were followed up for three years. The questionnaire covered patient evaluation of oral function, chewing ability and denture related fit/pain problems or discomfort. Impact of the prosthesis on quality of life issues including being upset, embarrassed and finding life less satisfactory was also evaluated. Patient satisfaction scores were high after implant loading with no significant differences between the two implant groups. Walton el al. ${ }^{14}$ reported results in accordance with the previous studies. In a randomized trial, patient satisfaction and prosthetic outcomes of mandibular overdentures retained by one or two implants were compared. They reported a remarkable improvement in patient satisfaction with no significant differences between participants with respect to the number of implants.

\section{CONCLUSIONS}

Implant retained mandibular overdentures opposed by maxillary complete dentures in contrast to conventional complete dentures significantly improved maximum bite force and masticatory efficiency in addition to patient satisfaction. Single symphyseal retained overdentures were comparable to the two implant variety. Locator and bar attachments had comparable outcomes with the exception of hygiene difficulties in the bar group.

\section{ACKNOWLEDGMENT}

I would like to thank Dr. Amal Swelem for her dedication and sincere help in case selection and preparation throughout the different phases of this study. Appreciation and gratitude is also extended to colleagues in MInia University for their help in patient recruitment.

\section{REFERENCES}

1. Mojon P, Thomason JM, Walls AWG. The impact of falling rates of edentulism. Int J Prosthodont 2004;17:434-440.

2. Mericske-Stern RD, Taylor TD, Belser U. Management of the edentulous patient. Clin Oral Implants Res 2000;1:10825 .

3. Fontijn-Tekamp FA, Slagter AP, van der Bilt A, van't Hof MA, Witter DJ, Kalk W et al. Biting and chewing in overdentures, full dentures, and natural dentitions. J Dent Res. 2000;79:1519-1524.

4. Chen L, Xie Q, Feng H, Lin Y, Li J. The masticatory efficiency of mandibular implant-supported overdentures as compared with tooth-supported overdentures and complete dentures. J Oral Implantol 2002; 28: 238-243.

5. Naert I, Alsaadi G, Quirynen M. Prosthetic aspects and patient satisfaction with two implant-retained mandibular overdentures: a 10-year randomized clinical study. Int J Prosthodont .2004; 17: 401-410.

6. Feine JS, Carlsson GE, Awad MA, Chehade A, Duncan WJ, Gizani S, Head T, Heydecke G, Lund JP, MacEntee M, Mericske-Stern R, Mojon P, Morais JA, Naert I, Payne AG, Penrod J, Stoker GT, Tawse-Smith A, Taylor TD, Thomason JM, Thomson WM, Wismeijer D. The McGill consensus statement on overdentures. Mandibular two-implant overdentures as first choice standard of care for edentulous patients. Int J Oral Maxillofac Implants 2002;17:601-2.

7. Feine JS, Maskawi K, de Grandmont P, Donohue WB, Tanguay R, Lund JP. Within-subject comparisons of implant-supported mandibular prostheses: Evaluation of masticatory function. J Dent Res 1994;73:1646-1656.

8. Awad MA, Lund JP, Dufresne E, Feine JS. Comparing the efficacy of mandibular implant-retained overdentures and conventional dentures among middle-aged edentulous patients: satisfaction and functional assessment. Int $\mathbf{J}$ Prosthodont 2003;16:117-22.

9. de Grandmont P, Feine JS, Taché R, Boudrias P, Donohue WB, Tanguay R, Lund JP. Within-subject comparisons of implantsupported mandibular prostheses: psychometric evaluation. J Dent Res 1994;73:1096-104. 
10. Boretti G, Bickel M, Geering AH. A review of masticatory ability and efficiency. J Prosthet Dent 1995;74:400-3.

11. Walton JN, MacEntee MI, Hanvelt R. Cost analysis of fabricating implant prostheses. Int $\mathrm{J}$ Prosthodont 1996;9:271-276.

12. Carlsson GE, Kayser AF, Owall B. Current and future trends in prosthodontics. In: Owall B, Kayser AF, Carlsson GE (eds). Prosthodontics: Principles and Management Strategies. London: Mosby-Wolfe, 1996:237-249.

13. Alsabeeha NH, Payne AG, De Silva RK, Thomson WM. Mandibular single-implant overdentures: preliminary results of a randomised-control trial on early loading with different implant diameters and attachment systems. Clin Oral Implants Res. 2011;22:330-7.

14. Walton JN, Glick N, MacEntee MI. A randomized clinical trial comparing satisfaction and prosthetic outcomes with mandibular overdentures retained by one or two implants. Int J Prosthodont 2009; 22:331-339.

15. Kronstrom M, Davis B, Loney R, Gerrow J, Hollender L. A Prospective Randomized Study on the Immediate Loading of Mandibular Overdentures Supported by One or Two Implants; A 3 Year Follow-Up Report. Clin Implant Dent Relat Res.. 2014; 16: 323-329.

16. Abdelnabi MH. Effect of platform switching on immediately loaded implants splinted with bars; a split mouth study. EDJ. 2013; 59: 1041-1059.

17. Abdelnabi MH. Freestanding versus splinted immediately loaded implants inserted at a torque exceeding $35 \mathrm{Ncm}$; a clinical prospective study. EDJ. 2014; 60: 751-771.

18. Abdelnabi MH. Immediate versus conventional loading of single symphyseal implants retaining overdentures; a clinical prospective study. EDJ. 2015; 61: 667-682.

19. Engelen L, Fontijn-Tekamp FA, van der Bilt A. The influence of product and oral characteristics on swallowing. Arch Oral Biol. 2005;50:739-746.

20. Östman P-O, Wennerberg A, Albrektsson T. Immediate occlusal loading of NanoTite ${ }^{\mathrm{TM}}$ Prevail ${ }^{\circledR}$ Implants: A prospective 1-year clinical and radiographic study.Clin Implant Dent Relat Res. 2010; 12:39-47.

21. Liddelow, G, Henry P. A prospective study of immediately loaded single implant-retained mandibular overdentures: preliminary one year results. J Prosthet Dent .2007;97: 126-137.
22. Liddelow G, Henry P. The immediately loaded single implant-retained mandibular overdenture: a 36-month prospective study. Int J Prosthodont .2010;23:13-21.

23. Stefanescu DM, Anghel MA. Electrical methods for force measurement - A brief survey; Measurement.2013; 46 :949-959.

24. Geckili O, Bilhan H, Mumcu E, Dayan C, Yabul A, Tuncer N. Comparison of patient satisfaction, quality of life, and bite force between elderly edentulous patients wearing mandibular two implant-supported overdentures and conventional complete dentures after 4 years. Spec Care Dentist,2012; 32: 136-141.

25. Geckili O, Bilhan H, Mumcu E, Tuncer N. The Influence of Maximum Bite Force on Patient Satisfaction and Quality of Life of Patients Wearing Mandibular Implant Overdentures. J Oral Implantol: 2012; 38: 271-277.

26. Cheng T, Ma L, Liu X L, Sun GF, He XJ , Huo J Y, Wang YN. Use of a single implant to retain mandibular overdenture: A preliminary clinical trial of 13 cases. J Dent.2012;7: 261-266.

27. Cheng T1, Sun G, Huo J, He X, Wang Y, Ren YF. Patient satisfaction and masticatory efficiency of single implantretained mandibular overdentures using the stud and magnetic attachments. J Dent. $2012 ; 40: 1018-23$.

28.Hatch JP, Shinkai RSA, Sakai S, Rugh JD, Paunovich ED. Determinants of masticatory performance in dentate adults. Arch Oral Biol. 2000;46:641-648.

29. Bakke M. Bite force and occlusion. Semin Orthod. 2006;12:120-126.

30.Slagter AP, Bosman F, van der Glas HW, van der Bilt A. Human jaw elevator muscle activity and food comminution in the dentate and edentulous state. Arch Oral Biol. 1993; 38:195-205.

31. van Kampen FMC, van der Bilt A, Cune MS, Bosman F. The influence of various attachment types in mandibular implant-retained overdentures on maximum bite force and EMG. J Dent Res. 2002;81:170-173.

32. Ahlberg JP, Kovero OA, Hurmerinta KA, Zepa I, Nissinen MJ, Kononen MH. Maximal bite force and its association with signs and symptoms of TMD, occlusion, and body mass index in a cohort of young adults. Cranio. 2003;21:248- 252 .

33. Granger MW, Buschang PH, Throckmorton GS, Iannaccone ST. Masticatory muscle function in patients 
with spinal muscular atrophy. Am J Orthod Dentofac Orthop. 1999;115:697-702.

34. Helkimo E, Carlsson GE, Helkimo M. Bite force and state of dentition. Acta Odontol Scand. 1977;35:297-303.

35. Fontijn-Tekamp FA, Slagter AP, van't Hof MA, Geertman ME, Kalk W. Bite forces with mandibular implant retained overdentures. J Dent Res. 1998;77:1832-1839.

36. Ferrario VF, Sforza C, Serrao G, Dellavia C, Tartaglia GM. Single tooth bite forces in healthy young adults. J Oral Rehabil. 2004;31:18-22.

37. Shinogaya T, Bakke M, Thomsen CE, Vilmann A, Matsumoto M. Bite force and occlusal load in healthy young subjects - a methodological study. Eur J Prosthodont Restor Dent. 2000;8:11-15.

38. Ikebe K, Nokubi T, Morii K, Kashiwagi J. Association of bite force with ageing and occlusal support in older adults. J Dent. 2005;33:131-137.

39. Heckmann SM, Heussinger S, Linke JJ, Graef F, Pro schel PA. Improvement and long-term stability of neuromuscular adaptation in implant-supported overdentures. Clin Oral Implants Res. 2009;20:1200-1205.

40. van der Bilt A. Assessment of mastication with implications for oral rehabilitation: a review. J Oral Rehabil.2011; 38:754-780.

41. van der Bilt A, Tekamp FA, van der Glas HW, Abbink JH. Bite force and EMG during maximum unilateral and bilateral clenching. Eur J Oral Sci. 2008;116:217-222.

42. Bilhan H, Geckili O, Mumcu E, Cilingir A, Bozdag E. The influence of implant number and attachment type on maximum bite force of mandibular overdentures: a retrospective study. Gerodontology,2012; 29: e116-e120.

43. Miyaura K, Matsuka Y, Morita M, Yamashita A, Watanabe T. Comparison of biting forces in different age and sex groups: a study of biting efficiency with mobile and nonmobile teeth. J Oral Rehabil. 1999;26:223-227.

44. Eerikäinen E, Könönen M. Forces required by complete dentures for penetrating food in simulated function. J Oral Rehabil. 1987;14:607-613.

45. Bakke M, Holm B, Gotfredsen K. Masticatory function and patient satisfaction with implant-supported mandibular overdentures: a prospective 5-year study. Int J Prosthodont. 2002;15:575-581.

46. van der Bilt A, Burgers M, van Kampen FMC, Cune MS. Mandibular implant-supported overdentures and oral function. Clin Oral Implants Res. 2010;21:1209-1213.

47. van Kampen FMC, van der Bilt A, Cune MS, FontijnTekamp FA, Bosman F. Masticatory function with implantsupported overdentures. J Dent Res. 2004;83:708-711.

48. Tang L, Lund JP, Taché R, Clokie CM, Feine JS. A withinsubject comparison of mandibular long-bar and hybrid implant-supported prostheses: evaluation of masticatory function. J Dent Res 1999; 78:1544-53.

49. Fontijn-Tekamp FA, Slagter AP, van't Hof MA, Kalk W, Jansen JA. Pain and instability during biting with mandibular implant-retained overdentures. Clin Oral Implants Res. 2001; 12: 46-51.

50. Helkimo E, Carlsson GE, Helkimo M. Chewing efficiency and state of dentition. A methodologic study. Acta Odontol Scand. 1978;36:33-41.

51. Hayakawa I, Watanabe I, Hirano S, Nagao M, Seki T. A simple method for evaluating masticatory performance using a color-changeable chewing gum. Int J Prosthodont. 1998;11:173-176.

52. Heath MR. The effect of maximum biting force and bone loss upon masticatory function and dietary selection of the elderly. Int Dent J. 1982;32:345-356.

53. Käyser AF, Hoeven v. Colorimetric determination of the masticatory performance. J Oral Rehabil. 1977;4:145-148.

54. Nakasima A, Higashi K, Ichinose M. A new, simple and accurate method for evaluating masticatory ability. J Oral Rehabil. 1989;16:373-380.

55. van der Bilt A, van der Glas HW, Mowlana F, Heath MR. A comparison between sieving and optical scanning for the determination of particle size distributions obtained by mastication in man. Arch Oral Biol. 1993;38:159-162.

56. Schimmel M, Christou P, Herrmann F, Müller F. A twocolour chewing gum test for masticatory efficiency: development of different assessment methods. J Oral Rehabil. 2007;34:671-678.

57. Speksnijder CM, Abbink JH, van der Glas HW, Janssen NG, van der Bilt A. Mixing ability test compared to a comminution test in persons with normal and compromised masticatory performance. Eur J Oral Sci. 2009;117:580586.

58. Liedberg B, Öwall B. Oral bolus kneading and shaping measured with chewing gum. Dysphagia. 1995; 10:101-106. 
59. Mioche L, Bourdiol P, Monier S. Chewing behaviour and bolus formation during mastication of meat with different textures. Arch Oral Biol. 2003;48:193-200.

60. Kapur KK, Soman SD. Masticatory performance and efficiency in denture wearers. J Prosthet Dent. 1964;14:687-694.

61. Geertman ME, Slagter AP, van Waas MAJ, Kalk W. Comminution of food with mandibular implant-retained overdentures. J Dent Res. 1994;73:1858-1864.

62. van der Bilt A, Speksnijder CM, de Liz Pocztaruk R, Abbink JH. Digital image processing versus visual assessment of chewed two-colour wax in mixing ability tests. J Oral Rehabil.2012; 39: 11-17.

63. Toman M, Toksavul S, Saracoglu A, Cura C, Hatipoglu A. Masticatory performance and mandibular movement patterns of patients with natural dentitions, complete dentures, and implant-supported overdentures. Int J Prosthodont. 2012; 25: 135-137.

64. Yurkstas AA, Emerson WH. Decreased masticatory function in denture patients. J Prosthet Dent. 1964;14:931934.

65. Elsyad MA, Hegazy SAF, Hammouda NI, Al-Tonbary GY, Habib AA. Chewing efficiency and electromyographic activity of masseter muscle with three designs of implantsupported mandibular overdentures. A cross-over study. Clin. Oral Impl. Res. 25, 2014, 742-748.

66. Awad MA, Feine JS. Measuring patient satisfaction with mandibular prostheses. Community Dent Oral Epidemiol 1998; 26:400-405.

67. Tang L, Lund JP, Tache R, Clokie CML, Feine JS. A withinsubject comparison of mandibular long-bar and hybrid implant-supported prostheses: Psychometric evaluation and patient preferences. J Dent Res 1997;76:1675-1683.

68. Bergman B, Carlsson GE. Review of 54 complete denture wearers - Patients' opinions 1 year after treatment. Acta Odontol Scand 1972;30:399-414.

69. Awad MA, Lund JP, Shapiro SH, Locker D, Klemetti E, Chehade A, Savard A, Feine JS. Oral health status and treatment satisfaction with mandibular implant overdentures and conventional dentures: a randomized clinical trial in a senior population. Int $\mathrm{J}$ Prosthodont. 2003; 16: 390-396.

70. Naert I, Gizani S, Vuylsteke M, van Steenberghe D. A 5-year prospective randomized clinical trial on the influence of splinted and unsplinted oral implants retaining a mandibular overdenture: Prosthetic aspects and patient satisfaction. J Oral Rehabil 1999;26:195-202. 